\title{
"OLD IS THE NEW NORMAL"
}

Dear Reader,

"Every cloud has a silver lining". A few "side effects" of the Covid era are welcome for diverse reasons. The "webinars explosion" on the internet and the new normal experience of "work from home" and online operations have produced "travel-saving", "time-saving" and "overhead saving" economics in corporate and academic environs. More particularly, the new "innovation culture" that has emerged in the small-medium pharma sector as the response to the patient needs in the pandemic tsunami is a welcome development. In

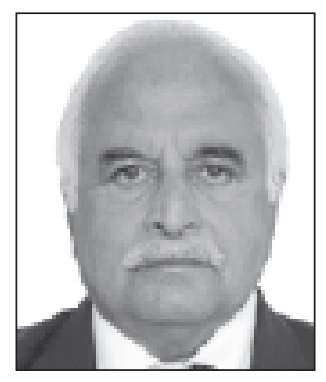
the wake of this repurposing spree, many "grandfather" drugs have found renewed interest. The revival of HCQ has been relatively short-lived compared to the "evergreen" Paracetamol which is being dispensed both to Covid patients in early stages and post vaccination to one and all. The medical profession as well as clinical researchers have taken to these proven remedies with low but well known (often nil) side effects. There are many examples. Recent research was shown that "Budesonide" inhaler (and the Budesonide and Formoterol inhalation) is an effective prophylactic as well as early stage Covid-19 therapy.

Colchicine is another drug reported in use from 1500 B.C. It was approved for medicinal use, though in a narrow safety efficacy range, since 1961. In recent times, Colchicine has emerged as the most commonly prescribed medication in USA, even before the outset of Covid. The modest "gout" drug has now been rediscovered in its new "Avtar" and has reborn in treatment of moderate symptomatic Covid-19 patients. Dexamethasone and Hydrocortisone have also emerged as useful agents in Covid therapy. The "Recovery Trial" found dexamethasone useful for patients on respiratory support. Hydrocortisone has also been used in managing septic shock in Covid patients. Indian Pharma Industry has been responding amazingly well by repurposing known drugs for affordable treatment of the alarming resurgence of Covid-19 extending from 2020 to 2021.

The "start-up" era of recent origin has been quick to reorient and reinvent themselves in responding to pandemic times. Newer medical devices and need-based diagnostic processes and products have come up through breakthrough innovations in recent times.

However, academic research institutions, except through some venture centres and start up initiatives, have not been forthcoming adequately to take advantage of these innovation opportunities. Low-hanging fruits in the form of incremental innovations (based on internet search of prior arts) are available as research topics, needed for immediate commercialization in industry. New drug delivery systems are also open for remodelling the repurposed drugs for current needs. The lack of adequate linkages with clinical research groups and investigators have kept the academic research institutions away from pursuing "me too" molecules, which could be extensions of newer large biological drugs like "mabs", "nibs" etc. This brings us back to our 
earlier clarion call to enhance and enlarge tie-ups and research cooperation between Industry-academia, clinical research, medical profession, medical devices and engineering research industry groups. The "silver lining" emerging from the "Covid cloud" is ideal for pharma-bio researchers to ride on by undertaking need-based innovation projects to meet current market expectations.

Further to the mad rush for Remdesivir, Gilead has issued a press release on availability of Remdesivir, even though Remdesivir is acknowledged as only helping to cut the hospital stay by 5 days. Of late, considerable interest has emerged among Researchers, Clinicians, pharma industry and physicians on MOLNUPIRAVIR, an oral drug for treatment of Covid-19 and the variants / mutants. There is opportunity for pharma researchers in the academic corridors to undertake work on newer formulations of useful molecules like Molnupiravir.

Dr. Gopakumar G. Nair

Editor Indian Drugs

https://doi.org/10.53879/id.58.02.p0005

About The Editor
Dr Gopakumar G Nair is a Ph.D in Organic Chemistry (1966) from National Chemical -University).
He was a Post-Doctoral fellow at IIT Bombay, Powai (1967) before joining the Pharma Industry. He
was Director of Bombay Drug House P. Ltd., later Chairman of BDH Industries Ltd. as well as CMD
of Bombay Drugs \& Pharma Ltd., which was merged with Strides Arcolab Ltd. in 2001. Dr. Nair
served IDMA as office bearer for many years from 1972 onwards and was Chairman of various
Committees for nearly 4 decades. He was the President of IDMA in 1999/2000. Currently, Dr. Nair
is the Chairman of the IPR Committee in IDMA.
Having moved into the Intellectual Property field, he was the Dean of IIPS (Institute of Intellectual
Property Studies) at Hyderabad in 2001/2002. Later, he set up his own boutique IP firm, Gopakumar
Nair Associates, as well as Gnanlex Hermeneutics Pvt. Ltd., having done his L.L.B. from Mumbai
University. He is also CEO of Patent Gurukul and President of Bharat Education Society, Kurla,
Mumbai, managing many educational institutions in and around Mumbai.
प

If you would like to comment on the editorial please write to us at publications@idmaindia.com 